\title{
Hepatocarcinoma Discrimination by Ratiometric Lipid Profiles Using Tip-Contact Sampling/Ionization Mass Spectrometry
}

Xiaoming Chen ${ }^{\dagger}$, Jiaqi Gao ${ }^{\ddagger}$, Tao Wang ${ }^{\dagger}$, Xinrong Jiang ${ }^{\dagger}$, Jiang Chen ${ }^{\ddagger}$, Xiao Liang ${ }^{\ddagger}$, Jianmin $\mathrm{Wu}^{\dagger *}$

†Institute of Analytical Chemistry, Department of Chemistry, Zhejiang University, Hangzhou, 310058, P. R. China, Email: wjm-st1@zju.edu.cn.

*Department of General Surgery, Sir Run Run Shaw Hospital, School of Medicine, Zhejiang University, Hangzhou 310016, P. R. China, Email: srrshlx@zju.edu.cn. 


\section{Table of Contents}

\section{Supplementary Experimental Procedures}

Materials and Reagents

Fabrication of SiNWs@ rGO chip

Tip-contact sampling (TCS) process for in situ lipidomic extraction

TCSI-MS detection and TCSI-MS imaging

H\&E stain of HCC tissue

Statistical analysis

\section{Supplementary Results and Discussion}

Synergistic effect of SiNWs and rGO in TCSI-MS

Lipid structure identification

\section{Supplementary Figures and Tables}

Supplemental Figure S1.45-tilted SEM images of SiNWs and SiNWs@rGO

Supplemental Figure S2. Mass spectra of a clinical HCC tumor tissue acquired through TCSI-MS by Si@rGO, SiNWs and SiNWs@rGO and summary of total ion intensity and number of signals

Supplemental Figure S3. Representative mass spectra detected on $T, P T$ and $N$ of specimen no. 1 at the FA, PE, PI, SM \& PC and TG range

Supplemental Figure S4. Distribution of relative standard deviation (RSD) of the signal intensities of lipid molecules after different normalization methods

Supplemental Figure S5. LDA result of $T, P T$ and $N$ groups based on 86 adjacent dual-peaks' ratio values when $T, P T$ and $N$ were presumed as two distinctive groups

Supplemental Figure S6. Bar graphs of feature ratios which were selected through two-sample $\mathrm{t}$ test and scatter graphs of 22 feature ratio values on $T, P T, N(\mathrm{p}<0.01)$

Supplemental Figure S7. LDA result of $T, P T$ and $N$ groups based on 114 peaks Supplemental Figure S8. Bar graphs of feature peaks which were selected through two-sample t test $(\mathrm{p}<0.01)$

Supplemental Figure S9. Magnified mass spectra of lipid profiles at the $m / z$ range of 8 pair dual-peaks, pearson correlation matrix among 22 feature ratios and scheme of linoleic acid metabolism in the liver

Supplemental Figure S10. Representative mass spectra detected on region $1(T)$ and region $2(P T)$ at the PE, PI and SM \& PC range of specimen no. 21; Single-peak 
digital imaging result of C18:2, C18:1, C20:4 and C20:4 of no. 21 HCC tissue sample Supplemental Table S1. Demographic information of 20 HCC patients

Supplemental Table S2. Detailed diagnostic information of HCC patients

Supplemental Table S3. MS/MS fragmental information of different types of lipid species

Supplemental Table S4. p value summary of feature ratios calculated with two-sample t test

Supplemental Table S5. p value summary of feature peaks calculated with two-sample $\mathrm{t}$ test

\section{Supplementary Reference}




\section{Supplementary Experimental Procedures}

\section{Materials and Reagents}

Silicon wafers were purchased from Xihe Ruida Technology Co., Ltd. (Beijing, China) and graphene oxide (GO) sol was purchased from Chengdu institute of Organic Chemistry, Chinese Academy of Science (CAS). Lauric acid (C12:0), palmitic acid (C16:0), stearic acid (C18:0), arachidic acid (C20:0), tetracosanoic acid (C24:0), 1, 2-dipalmitoly-sn-glycero-3-phosphoethanolamine (DPPE 16:0/16:0) were purchased from Aladdin Co. (Shanghai, China). The $\alpha$-cyano-4-hydroxycinnamicacid (CHCA) and the peptide calibration standards (700-3500 Da) were the products from Bruker Daltonics Co. (Germany). (3-aminopropyl) triethoxysilane (APTES) were purchased from Sigma-Aldrich Co. (Shanghai, China). H\&E staining kit was purchased from Beyotime Biotechnology Co. (Shanghai, China). Human hepatocellular carcinoma tissue samples, including tumor, adjacent para-tumor tissues and normal tissues around the cutting margin, were obtained from hepatocellular carcinoma patients who undergo surgery. All clinical samples were provided by Sir Run Run Shaw Hospital. Informed consent was obtained from each patient and monitored by the Sir Run Run Shaw Hospital Ethics Review Board.

\section{Fabrication of SiNWs@rGO}

SiNWs were fabricated via one-step metal-assisted chemical etching (MACE) method $^{S 1}$ followed with alkali post etching method. ${ }^{S 2}$ In brief, p-type $\mathrm{Si}<5-10 \Omega \cdot \mathrm{cm}>$ wafers were reacted with the etching solution containing 4.8 M HF (CAUTION: HF is highly toxic and volatile, which is harmful to respiratory system and skeleton. Contacting HF with skin should be avoided and all the etching experiments need to be handled carefully in the fume hood) and $0.02 \mathrm{M} \mathrm{AgNO}_{3}$ for $15 \mathrm{~min}$. After etching, the wafers were washed repeatedly with water and then were immersed in dilute $\mathrm{HNO}_{3}(1: 1$ $\mathrm{v} / \mathrm{v}$ ) for $1 \mathrm{~h}$ to dissolve the Ag catalyst. Then the material was treated with $5 \% \mathrm{HF}$ (solvent: $\mathrm{EtOH}$ ) for $10 \mathrm{~min}, 0.1 \% \mathrm{KOH}$ aqueous solution added with $10 \% \mathrm{EtOH}$ for another $60 \mathrm{~s}$ at $300 \mathrm{~K}$ in sequence. Post etching with $\mathrm{KOH}$ would lead to a tip structure on SiNWs. ${ }^{\mathrm{S} 2}$ After that, the as-prepared SiNWs wafer was treated with $\mathrm{O}_{2}$ plasma for $60 \mathrm{~s}$ and was thereafter reacted with 2\% (3-aminopropyl) triethoxysilane (APTES) in toluene solution for $15 \mathrm{~min}$. Then graphene oxide (GO) solution dissolved in $50 \%$ EtOH was deposited on a squared SiNWs-APTES chip to a final coverage concentration of $8 \mathrm{ng} / \mathrm{mm}$. To reduce GO into $\mathrm{rGO}$, chips were reacted with hydrazine hydrate at $70^{\circ} \mathrm{C}$ for $1 \mathrm{~h}$. For comparison, Si wafer was also loaded with rGO.

\section{Tip-Contact Sampling (TCS) Process for In-Situ Lipidomic Extraction}

All tissues applied for TCS removed from clinical surgery were firstly washed by DI water to get rid of adsorptive blood. Though they were stored at $-80^{\circ} \mathrm{C}$ after being 
resected, each tissue sample needed to be thawed to the room-temperature condition, simulating the intraoperative environment. A SiNWs@ rGO chip $(2.5 \mathrm{~mm} \times 2.5 \mathrm{~mm})$ was fixed at the bottom of mechanical arm and was pressed onto the surface of tissue solid tightly for $60 \mathrm{~s}$, which was controlled by an automated dip coater (San-Yan Co., Shanghai). Then the chip was washed with pure water thoroughly for $10 \mathrm{~s}$ and dried under room temperature. For each liver tissue sample, three SiNWs@ rGO chips were used for molecular extraction, representing its overall information. Another rectangle $2.5 \mathrm{~mm} \times 10 \mathrm{~mm}$ chip was simultaneously applied for TCS on the cancerous and adjacent normal part of specimen no. 21. Following the TCS process, SiNWs@rGO chips were stored in the desiccator before MS detection.

\section{TCSI-MS Detection and TCSI-MS Imaging}

After TCS process, SiNWs@rGO chips were stuck onto the custom-made aluminum plate with carbon conductive adhesive tape and inserted into the instrument. Mass spectra were obtained on the UltrafleXtreme MALDI-TOF/TOF instrument (Bruker Daltonics Co.) equipped with a $355 \mathrm{~nm} \mathrm{Nd:YAG} \mathrm{laser} \mathrm{beam} \mathrm{(pulse} \mathrm{energy}<500 \mu \mathrm{J}$ with a pulse width $=3 \mathrm{~ns}$ ). The diameter of the laser spot in circular shape was set at $\sim 100 \mu \mathrm{m}$. The relative laser pulse energy was set at $81.1 \%$ of the maximum energy for lipids detection on tissue samples. The ions that resulted from a $100 \mathrm{~ns}$ pulse ion extraction were subjected to an electric field of $2.25 \mathrm{kV}$ between ion source 1 and ion source 2 and were analyzed in reflective mode. The generated spectra were obtained after 500 laser shots of the spot. Mixture of C12:0, C16:0, C18:0, C20:0, C24:0 and DPPE 16:0/16:0 dissolved in $\mathrm{CHCl}_{3}$ with each component's concentration equals to 1 $\mathrm{mg} / \mathrm{mL}$ was used for negative-ion mode mass calibration while CHCA and the peptide calibration standards (700-3500 Da) were used as calibrators in positive ion mode. MS spectra acquisition should be accomplished after mass calibration. Mass range was set at $m / z=200-1000$ and $\mathrm{m} / z=700-1000$ for negative-ion and positive-ion detection modes, respectively. The structural identification of the lipids was realized through MALDI-TOF/TOF detection and LIPID MAPS database exploration (http://www.lipidmaps.org). To complete the MS imaging process, SiNWs@ rGO chip was scanned at 1200 dpi resolution after TCS procedure. Subsequently, FlexImaging software (Bruker Daltonics Co.) was controlled for MS imaging with optimized detection parameters when the spatial resolution was set at $200 \mu \mathrm{m}$. The targeting "dual-peak" data list was export from FlexImaging software (Bruker Daltonics Co.) for ratio calculation and digital imaging by MATLAB software.

\section{H\&E stain of HCC tissue}

No. 21 tissue sample was sliced into $12 \mu \mathrm{m}$ sections using a Leica CM30503 cryostat (Leica Microsystems, Germany) without adding any embedding agent. Then tissue slice was mounted onto glass slides. H\&E stain was completed following its standard protocol of the H\&E stain kit. Briefly, tissue section was firstly fixed with $95 \% \mathrm{EtOH}$ for $10 \mathrm{~min}$. Then it was stained with hematoxylin for $10 \mathrm{~min}$. After that, it was 
immersed in deionized water for $10 \mathrm{~min}$ and carefully rinsed with deionized water to wash off the hematoxylin that was not bounded to cells. Then the section was rinsed with $95 \% \mathrm{EtOH}$ for $5 \mathrm{~s}$, followed with staining in eosin for $1 \mathrm{~min}$. Finally, it was rinsed with deionized water, washed with $75 \% \mathrm{EtOH}$ and waited to be dry for observation.

\section{Statistical analysis}

The acquired raw mass spectra were first pretreated with baseline subtraction in the FlexAnalysis 3.4 software (Bruker Daltonics Corp.). After MS/MS identification of detected peaks in negative and positive ion modes, the detected peaks were classified into different species of lipids: FA $(m / z=200-350)$, PE $(m / z=700-800)$, PI $(m / z=$ 800-920), SM $(m / z=700-770), \mathrm{PC}(\mathrm{m} / z=750-840)$ and TG $(m / z=820-970)$. [FA-H] $[\mathrm{PE}-\mathrm{H}]^{-},[\mathrm{PI}-\mathrm{H}]^{-},[\mathrm{SM}+\mathrm{K}]^{+},[\mathrm{PC}+\mathrm{Na}]^{+}[\mathrm{TG}+\mathrm{Na}]^{+}$ions were selected for further statistical analysis. These peaks were normalized into each lipid class by dividing the max value. Also, the ratios of the intensities of adjacent dual-peaks appeared in the mass spectra were all calculated. Using these features, LDA (canonical discrimination analysis using Fisher's method) were completed in MATLAB software when $T, P T$ and $N$ were presumed as three or two distinctive groups. Also, an artificial neural network (ANN) model with a multi-layer perception structure (number of hidden neurons $=5$ ) was built in the pattern recognition tool in MATLAB software based on the ratio dataset. In the ANN model, $T$ was set as positive while both $P T$ and $N$ were seen as negative parts. The training set occupied $70 \%$ of the dataset, while $15 \%$ data were used as the validation set and other $15 \%$ data were set as the testing set for evaluation of prediction accuracy. The dataset was composed of the averaged data of three replicates on each tissue sample. Through the ANN model, the confusion matrix and the receiver operating characteristic (ROC) curve can be obtained. ANN model was operated in five successive cycles to get the ranges of sensitivity, specificity, accuracy and AUC values. In order to explore the potential biomarkers, feature peaks and ratios were selected out through two-sample two-sided Student's t test $(\alpha=0.05)$ to differentiate between each two classes ( $T$ vs $P T, T$ vs $N$ and $P T$ vs $N$ ) when p value was set below 0.01. Pearson correlation matrix was completed in MATLAB software using these ratio values from all samples. 


\section{Supplementary Results and Discussion}

\section{Synergetic Effect of SiNWs and rGO in TCSI-MS}

Both SiNWs and rGO are excellent candidates for matrix-free MS detection. ${ }^{\mathrm{S} 3}$, 44 As shown in Figure S1, rGO appeared as a thin network at the surface of SiNWs, without destroying the structure of substrates. When applied for TCSI-MS, SiNWs and rGO were found to show synergetic effect for in situ lipid extraction and on-chip MS detection. Compared with bare SiNWs or Si@rGO, SiNWs@rGO can obtain more peaks with stronger signals on clinical HCC tissues (Figure S2), especially in positive-ion detection mode. Loading of rGO onto SiNWs can expand the detection coverage of lipid groups. Therefore, to acquire more dimensional data for multivariate analysis, TCSI-MS on HCC tissues were completed on SiNWs@ rGO chips.

\section{Lipid Structure Identification}

MS/MS experiments were conducted to allow the peak assignment of lipids and characterization of their structure and composition. Using the data of the MS/MS profile and the database search in http://www.lipidmaps.org as well as referring to reported work, ${ }^{\mathrm{S} 5-\mathrm{S} 7}$ the identified molecules were assigned as phosphatidylinositol (PI), phosphatidylethanolamine (PE), phosphatidylcholine (PC), sphingomyelin (SM), phosphatidylserine (PS) and triacylglycerol (TG). Table S3 give detailed information of the peaks applied for MS/MS identification. FAs, PEs and PIs appeared as $[\mathrm{M}-\mathrm{H}]^{-}$ ions in the negative-ion mode mass spectra while most PCs, SMs, TGs and PSs adducted with $\mathrm{Na}^{+}$or $\mathrm{K}^{+}$ion in positive ion mode. Signals belonging to PE and PI classes tend to be found as cluster peaks with different saturations and different length of fatty acid chains. Thus, those peaks who cannot be identified using their tandem mass spectra due to the low abundance of the parent ions can be speculated according to their $\mathrm{m} / \mathrm{z}$ values. PC and SM share similar feature fragmental peaks such as $\mathrm{m} / \mathrm{z}=$ $184\left(\left[\left(\mathrm{CH}_{3}\right)_{3} \mathrm{~N}\left(\mathrm{CH}_{2}\right)_{2} \mathrm{PO}_{4} \mathrm{H}+\mathrm{H}\right]^{+}\right), m / z=163\left(\left[\left(\mathrm{CH}_{2}\right)_{2} \mathrm{PO}_{4} \mathrm{H}+\mathrm{K}\right]^{+}\right)$and $\mathrm{m} / z=147$ $\left(\left[\left(\mathrm{CH}_{2}\right)_{2} \mathrm{PO}_{4} \mathrm{H}+\mathrm{Na}\right]^{+}\right)$. The only difference between $\mathrm{PC}$ and $\mathrm{SM}$ was that $[\mathrm{M}+\mathrm{H}]^{+}$, $[\mathrm{M}+\mathrm{Na}]^{+},[\mathrm{M}+\mathrm{K}]^{+}$ions of PC molecules appeared at even $\mathrm{m} / z$ values, while the SM ions appeared at odd $\mathrm{m} / \mathrm{z}$ values due to the presence of a nitrogen atom in SM molecules. As for cluster peaks of TG molecules, $[\mathrm{M}+\mathrm{Na}]^{+}$and $[\mathrm{M}+\mathrm{K}]^{+}$ions mostly appeared simultaneously, whose relative intensity depends on the salt components at the tissue surface. 


\section{Supplementary Figures and Tables}

(a)

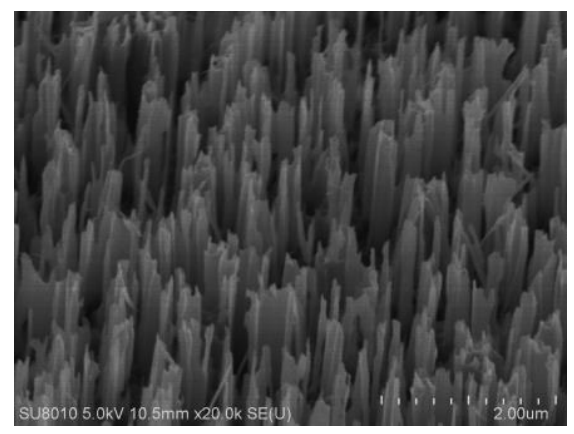

(b)

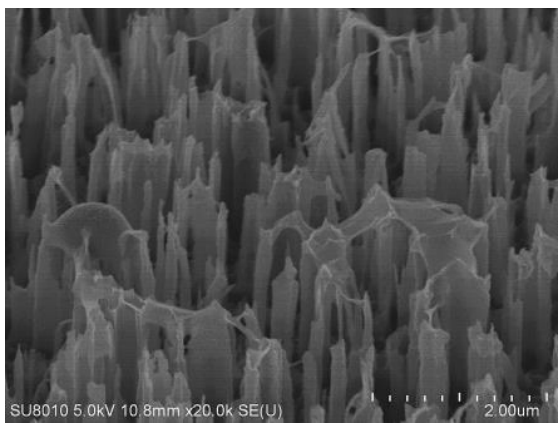

Figure S1.45-tilted SEM images of SiNWs (a) and SiNWs@rGO (b).

Negative ion mode

(a)

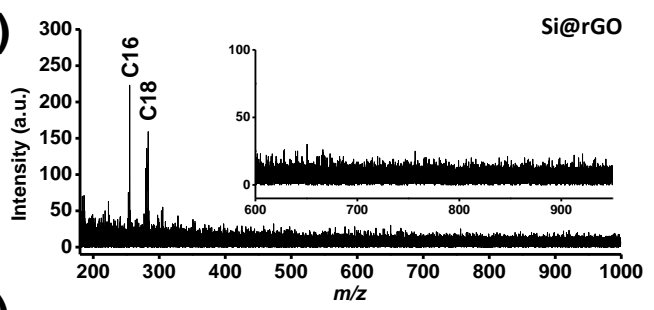

(c)
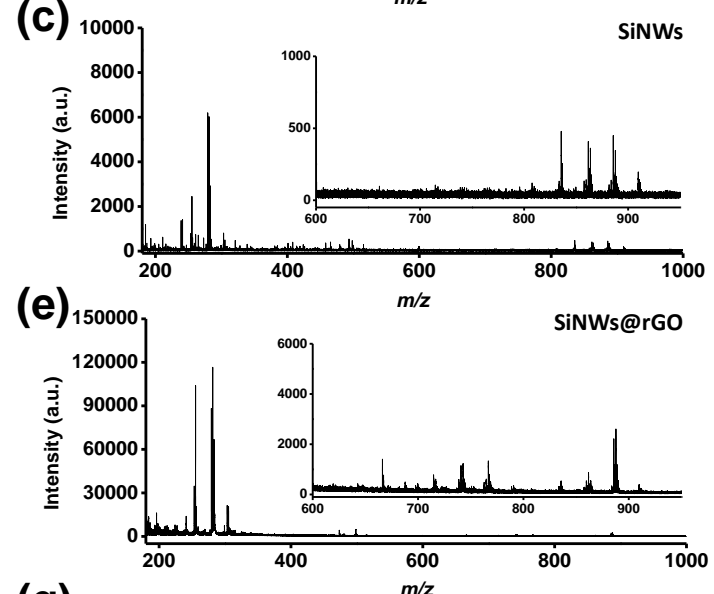

(g)

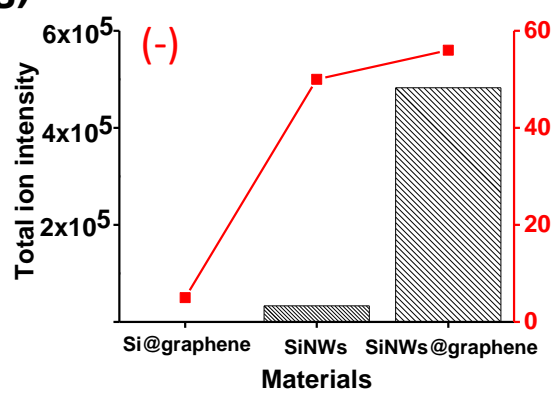

Positive ion mode

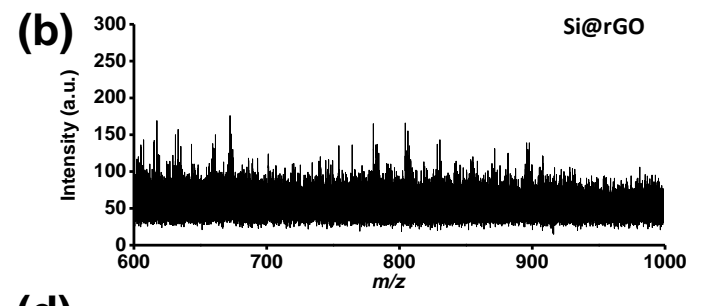

(d)

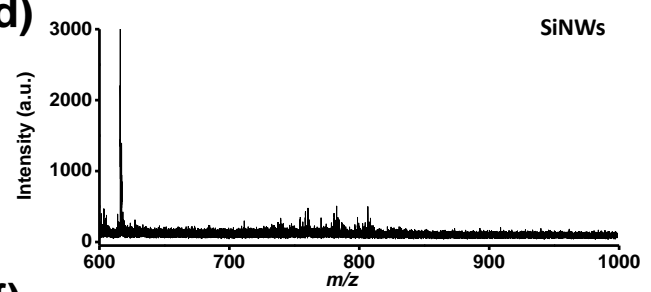

(f)

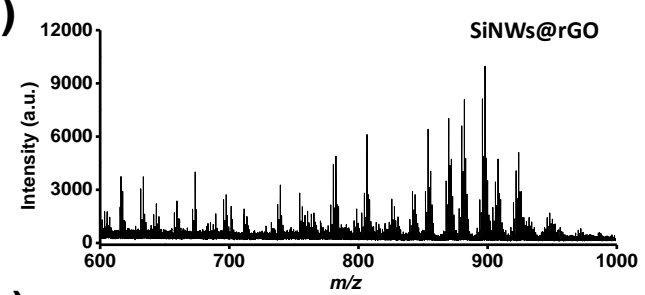

(h)

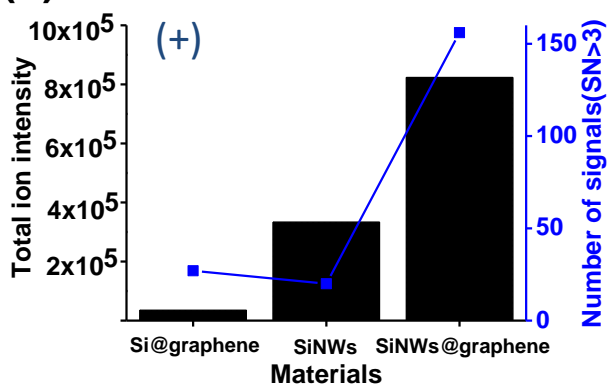

Figure S2. (a-f) Negative-ion (a, c, e) and positive-ion (b, d, f) mode mass spectra of a clinical HCC tumor tissue acquired through TCSI-MS by Si@rGO (a, b), SiNWs (c, d) and SiNWs@rGO $(\mathrm{e}, \mathrm{f}) .(\mathrm{g}, \mathrm{h})$ Total ion intensity and number of signals in negative ion $(\mathrm{g})$ and positive ion $(\mathrm{h})$ modes. Red line in (g) and blue line in (h) are corresponding to the number of detected signals. 
(a)

No.1-T

C18:1

(b) No.1-T

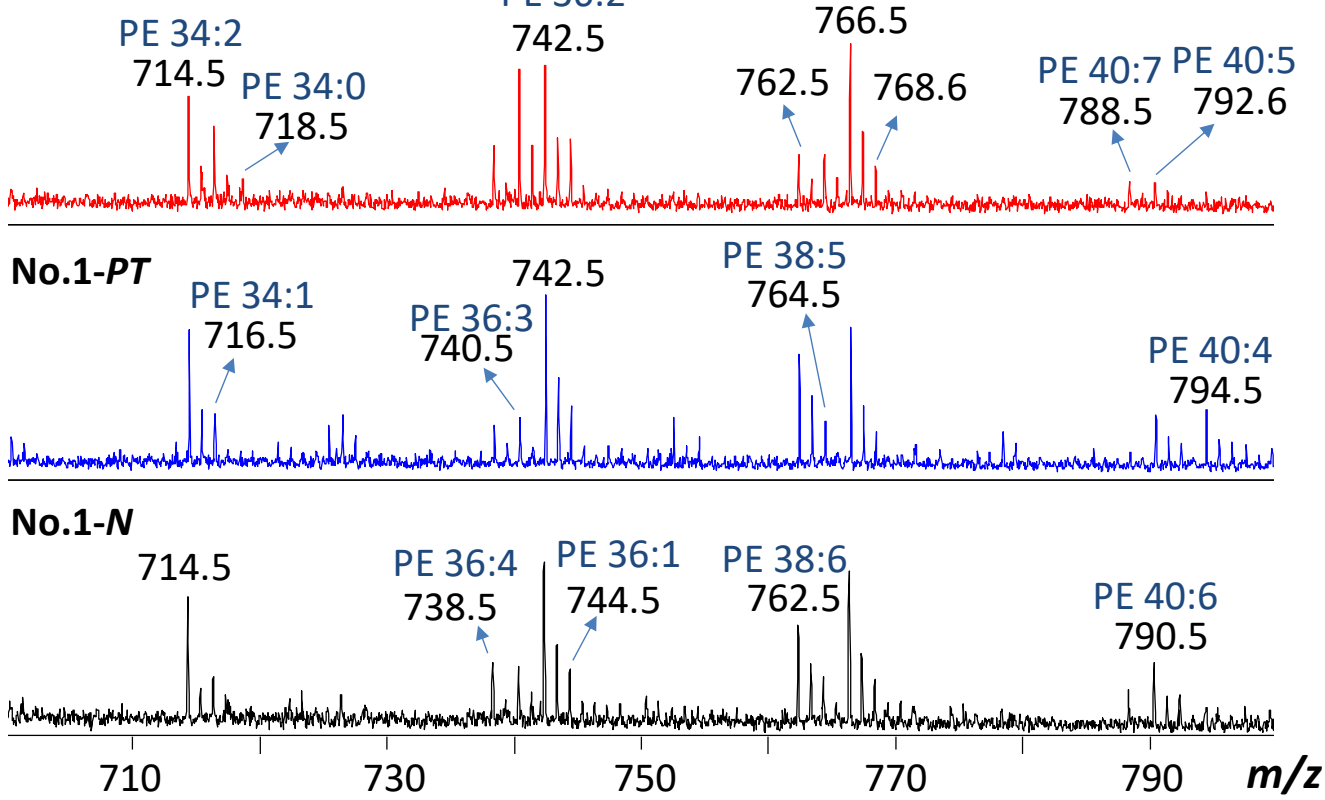


(c)

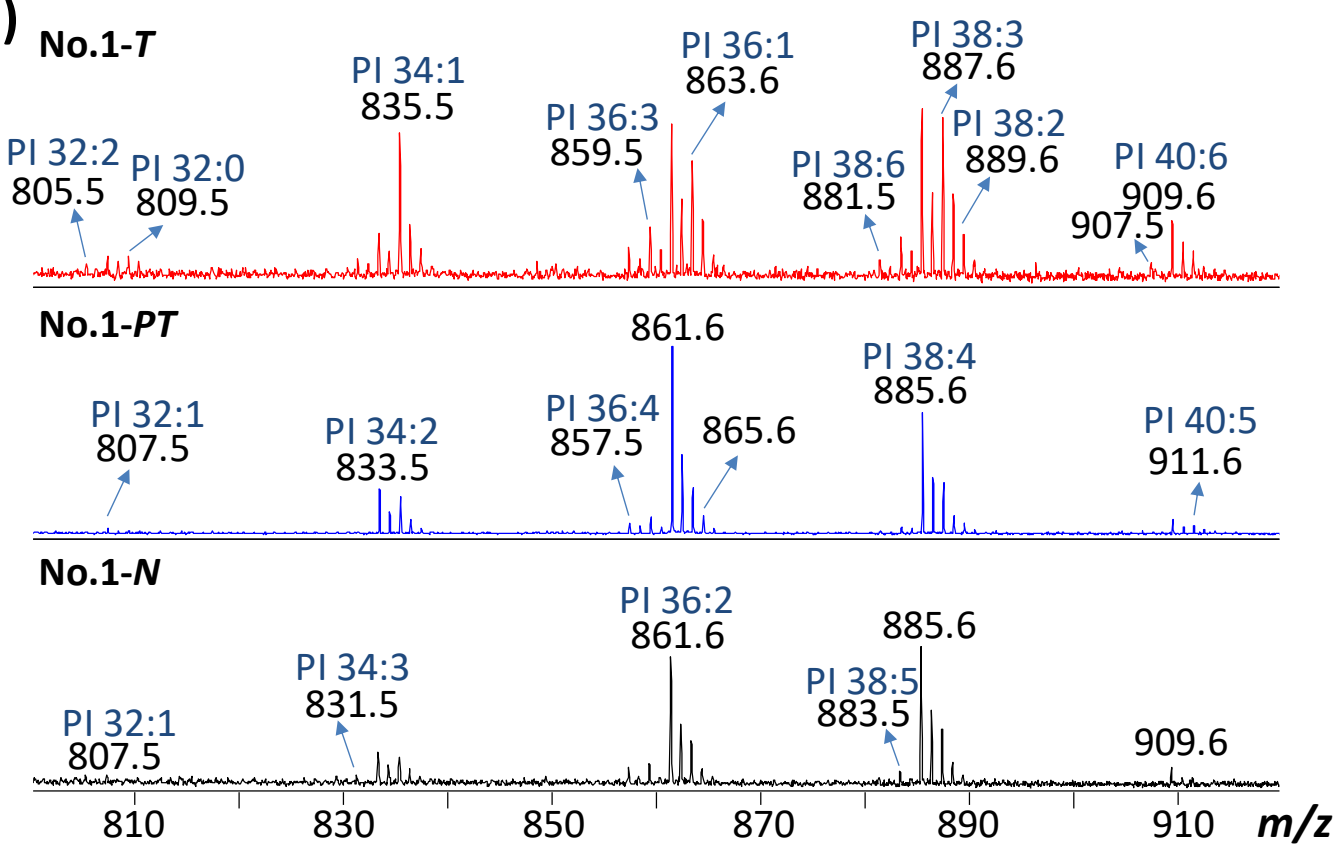

(d)

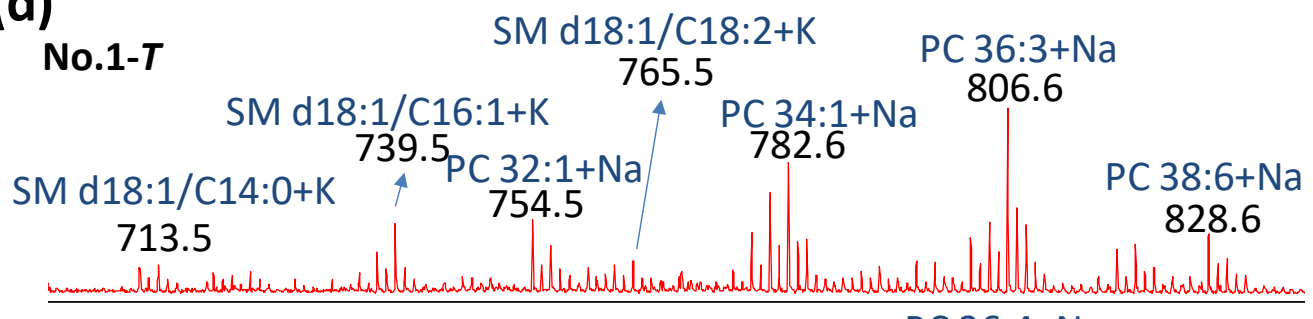

No.1-PT SM d18:1/C16:2+K PC 34:3+Na PC 36:4+Na
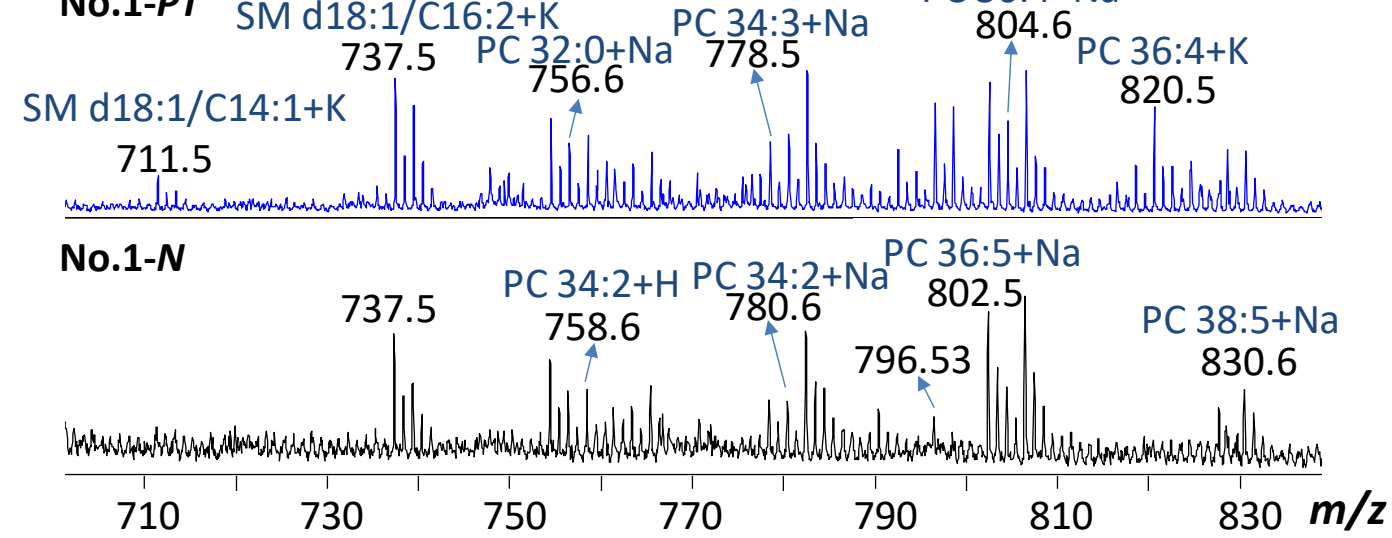
(e)

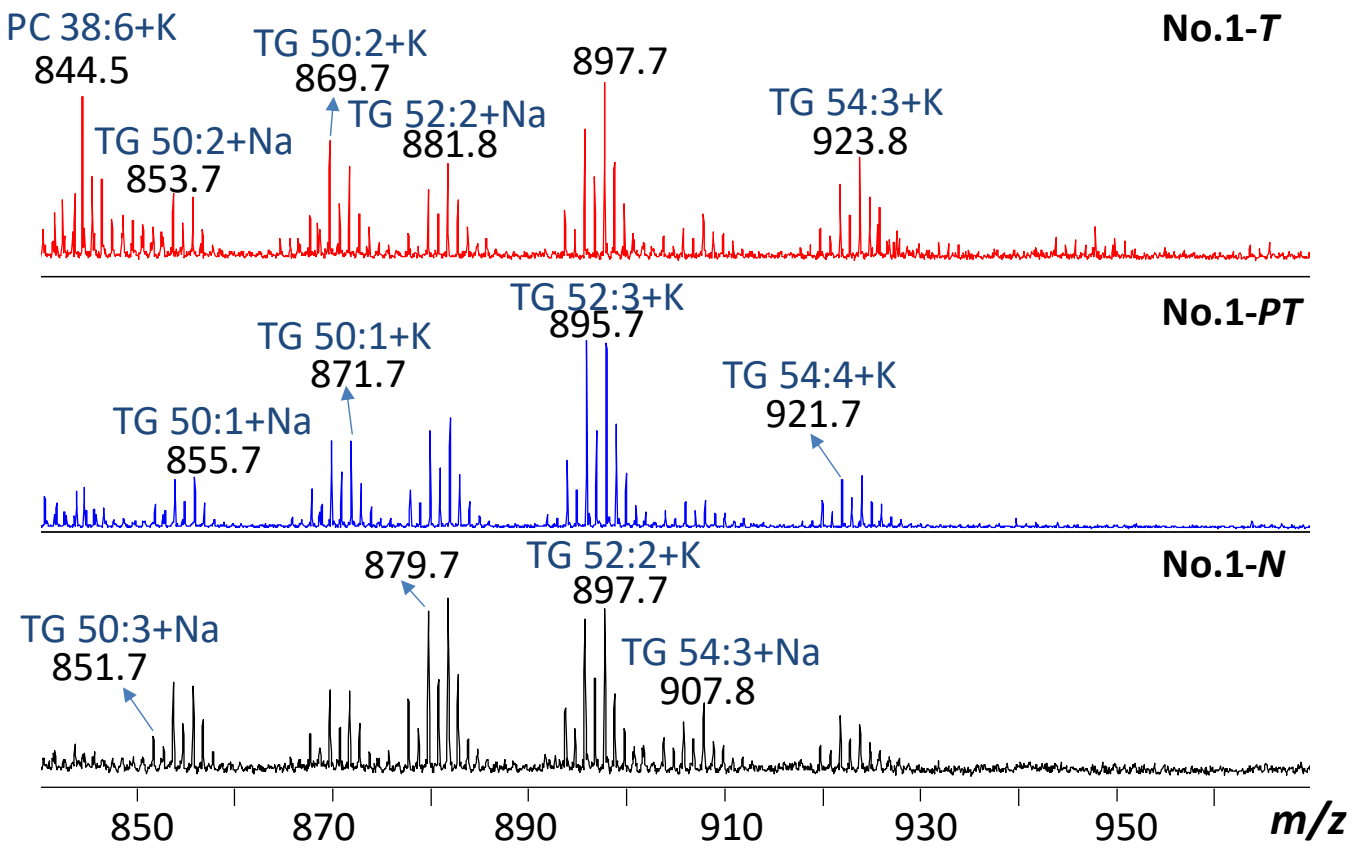

Figure S3. Representative mass spectra detected on $T, P T$ and $N$ of specimen no. 1 at the FA (a), PE (b), PI (c), SM \& PC (d) and TG (e) range. FA, PE and PI were detected as [M-H] $]^{-}$ions in negative ion mode while SM, PC and TG were detected as $[\mathrm{M}+\mathrm{H}]^{+},[\mathrm{M}+\mathrm{Na}]^{+}$or $[\mathrm{M}+\mathrm{K}]^{+}$ions in positive ion mode. Thus, text on the mass spectra, such as C16:0, PE 34:1, PI 34:1 were corresponding to [C16:0-H]', [PE 34:1-H] $]^{-}$, [PI 34:1-H] ${ }^{-}$and SM d18:1/C16:1+K, PC 34:1+Na, TG $52: 3+\mathrm{K}$ mean $[\mathrm{SM} d 18: 1 / \mathrm{C} 16: 1+\mathrm{K}]^{+}$, [PC $\left.34: 1+\mathrm{Na}\right]^{+}$, [TG $\left.52: 3+\mathrm{K}\right]^{+}$. Figure $\mathrm{S} 3$ can be seen as the magnified spectra of those in Figure 1.

(a)

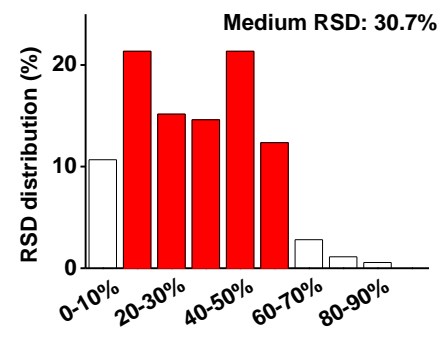

(b)

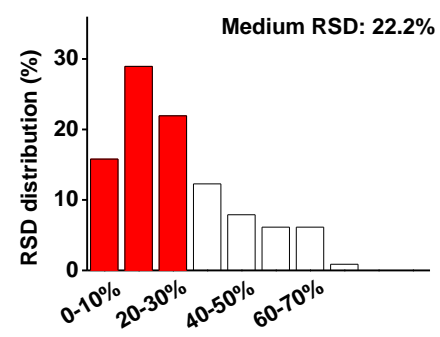

(c)

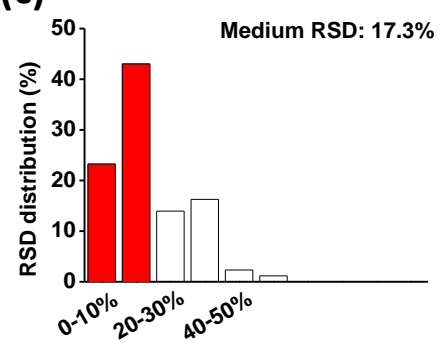

Figure S4. Distribution of relative standard deviation (RSD) of the signal intensities of lipid molecules after different normalization methods. (a) All detected ions $(S / N>3)$ were normalized within the detection range in positive or negative ion mode, (b) Ions were normalized within each class of lipids, (c) Ratio values of adjacent dual-peaks were calculated. The data used for statistical analysis were obtained in three batches using the same clinical normal liver sample, and three SiNWs@rGO chips were applied for TCSI in each batch. (Experiment interval between two bathes is more than two weeks). The percentage of RSD value that is lower than $30 \%$ in (a), (b) and (c) are $47.2 \%, 66.7 \%$ and $80.2 \%$, respectively. 
(a)

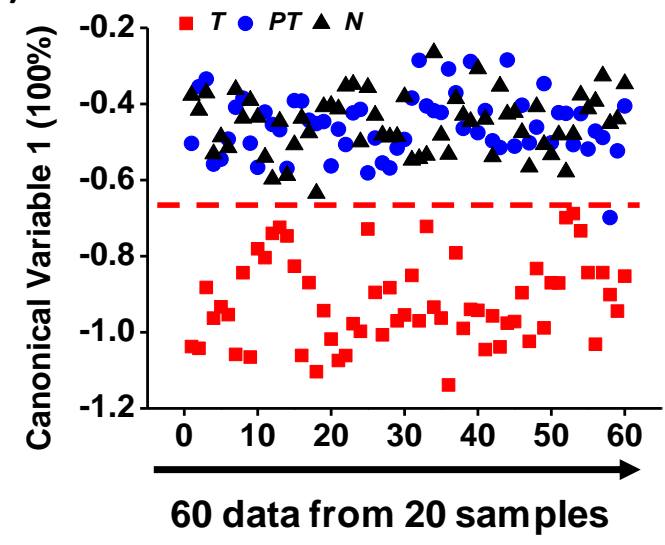

(b)

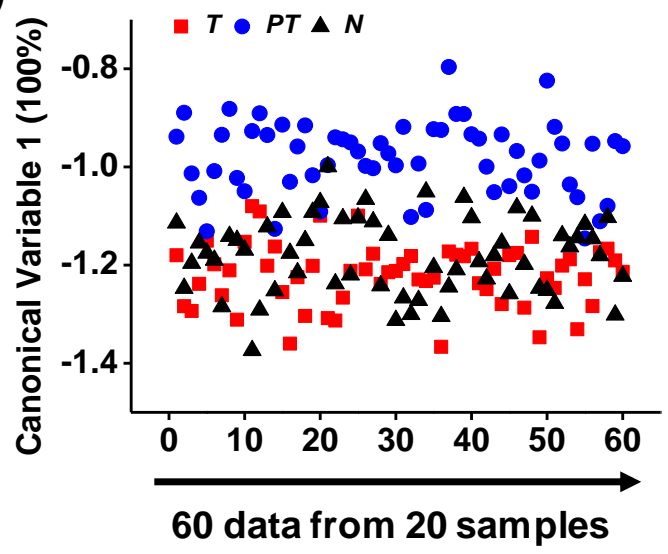

Figure S5. LDA result of $T, P T$ and $N$ groups based on 86 adjacent dual-peaks' ratio values when $T, P T$ and $N$ were presumed as two distinctive groups ( $T$ was set as group 1 and $P T+N$ were set as group 2 in (a), $P T$ was set as group 1 and $T+N$ were set as group 2 and in (b)). Triplicates were done for each tissue sample. Thus, 60 dots $(20 \times 3)$ can be found in each class $(T$ or $P T$ or $N)$ in the LDA plot score. Only one canonical variable equation was obtained when two groups were presumed.

(a)

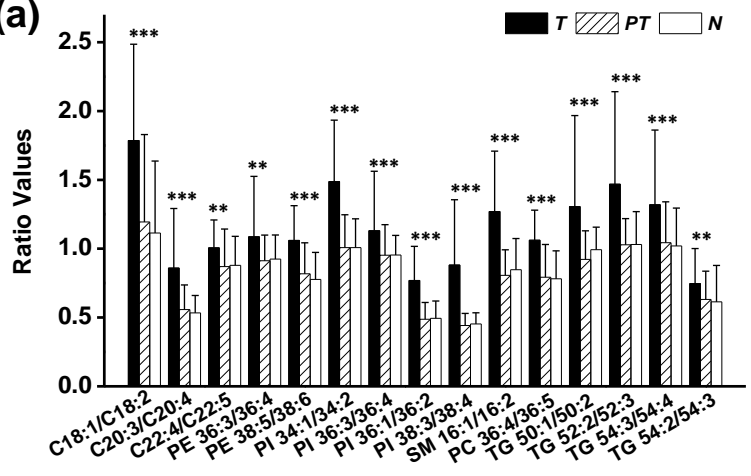

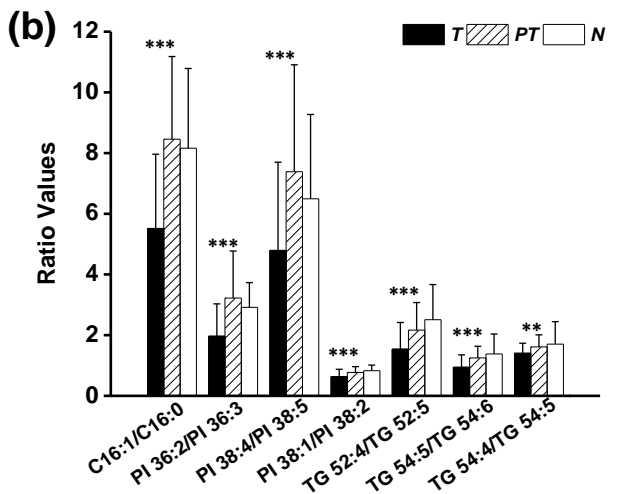

(c)
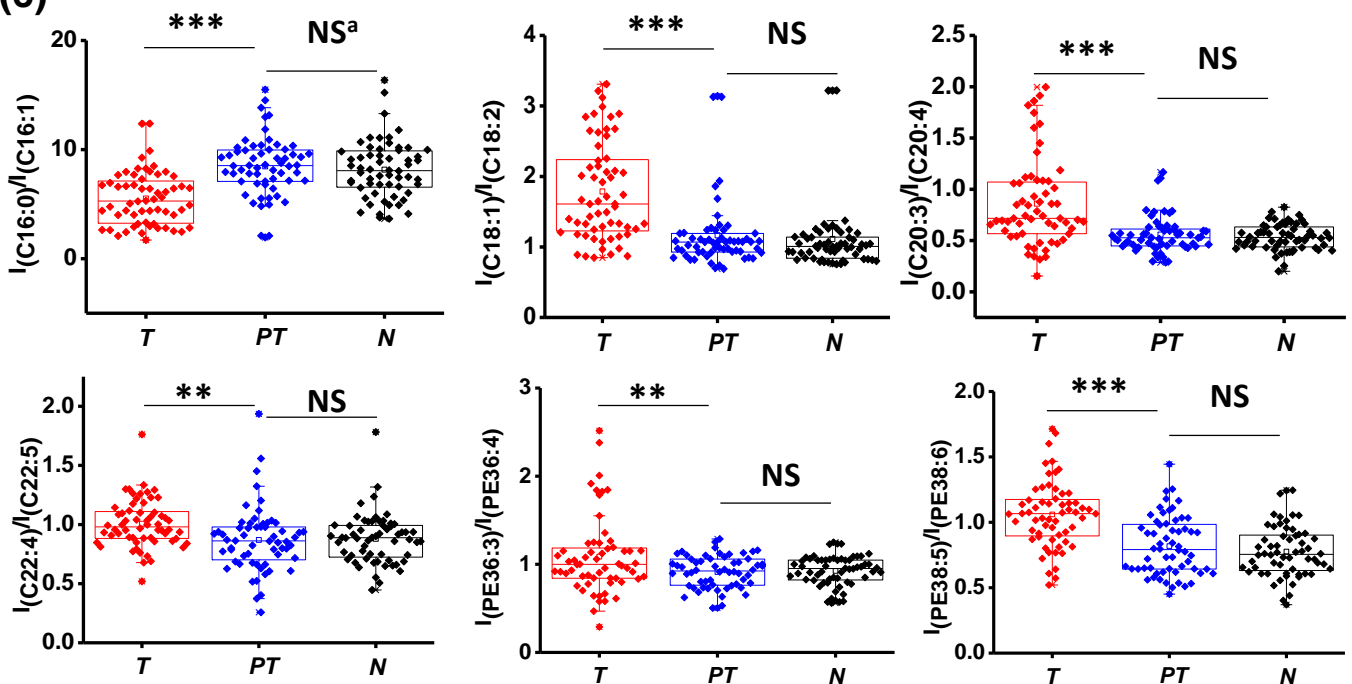

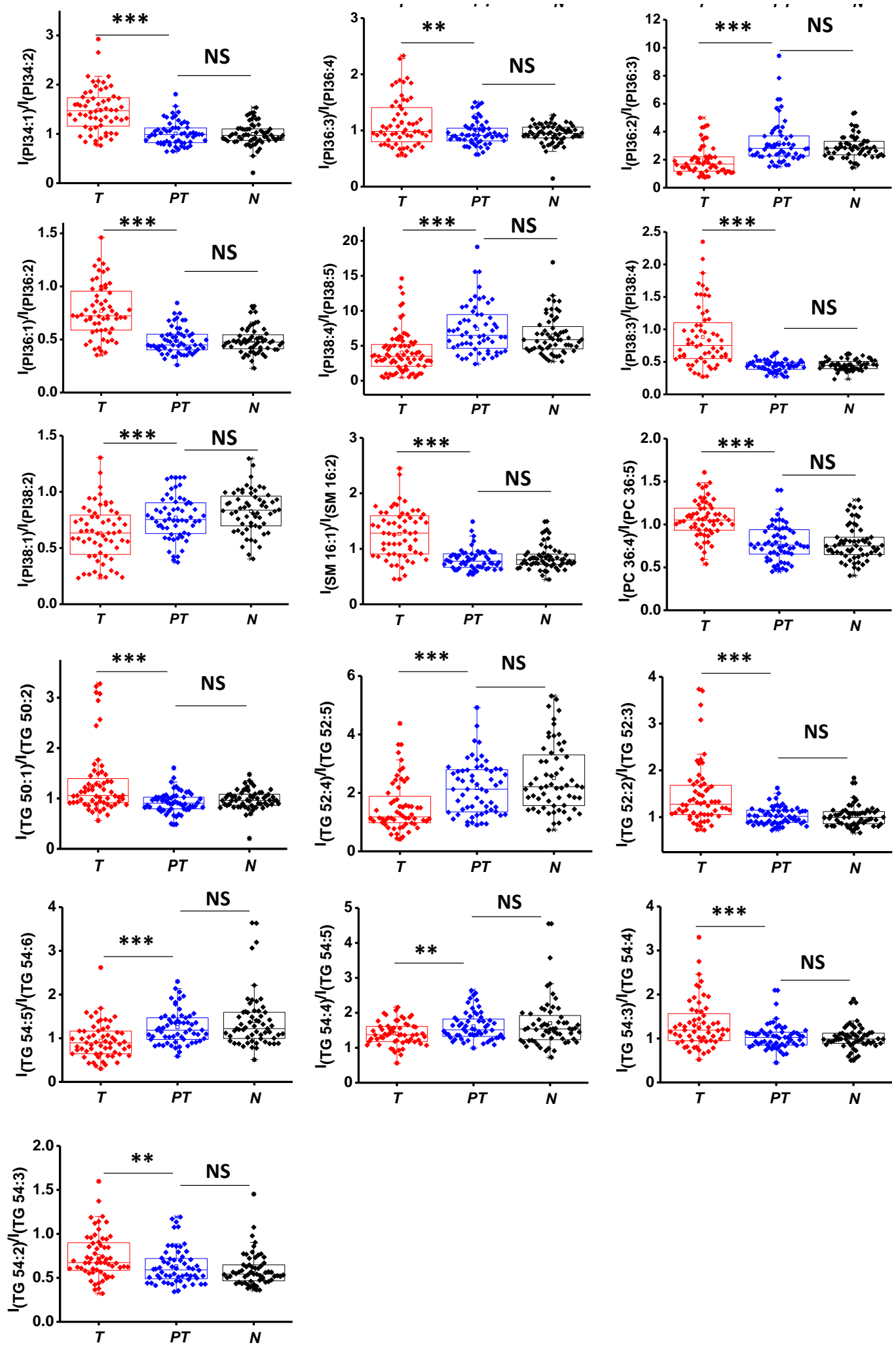

Figure S6. $(a, b)$ Bar graphs of feature ratios which were selected through two-sample $t$ test $(\mathrm{p}<$ 0.01). $\mathrm{p}<0.01^{* *}, \mathrm{p}<0.001^{* * *},{ }^{a} \mathrm{NS}$ means no significant difference $(\mathrm{p}>0.05)$. These ratios were up-regulated (a) or down-regulated (b) in the tumor tissues compared with adjacent 
para-tumor and normal tissues. (c) Scatter graphs of 22 feature ratio values on $T, P T, N$. Three independent tests were done for each tissue sample.

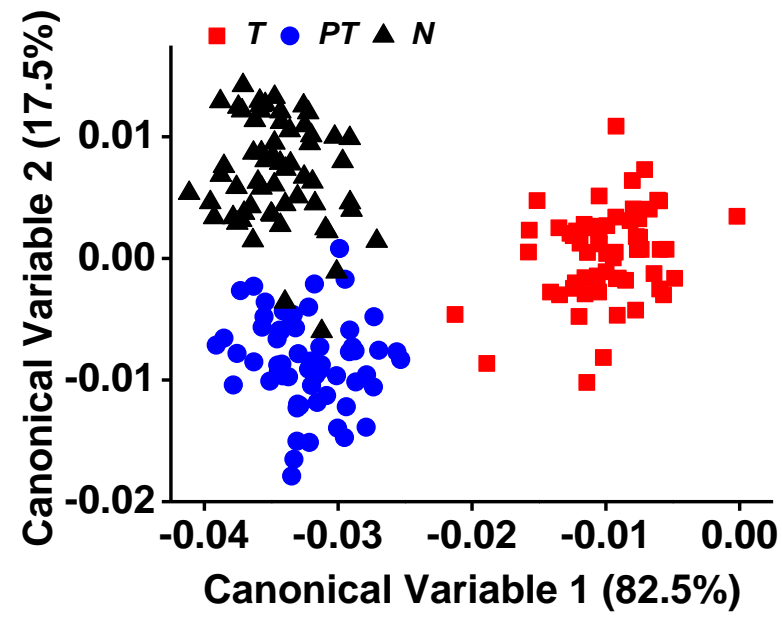

Figure S7. LDA result of $T, P T$ and $N$ groups based on 114 peaks. when $T, P T$ and $N$ were presumed as three distinctive groups. Triplicates were done for each tissue sample. Thus, 60 dots (20 $\times 3)$ can be found in each class $(T$ or $P T$ or $N)$ in the LDA plot score.

(a)

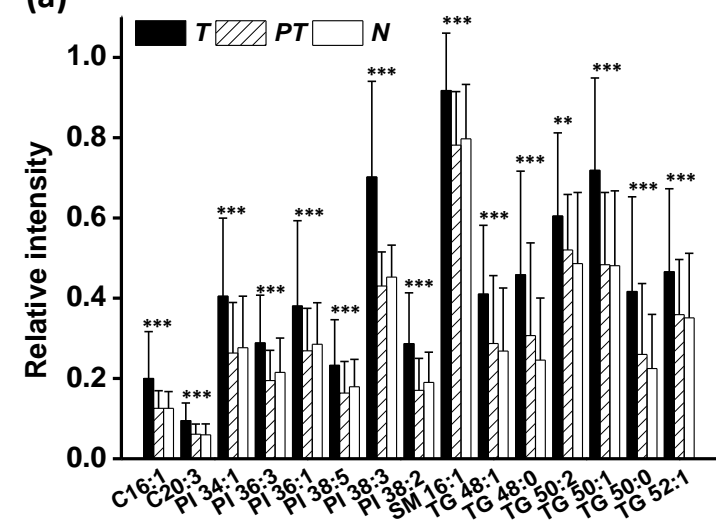

(b)

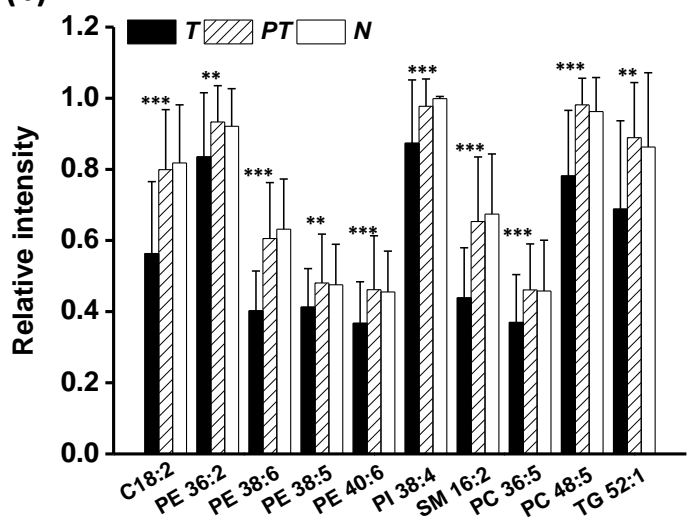

Figure S8. Bar graphs of feature peaks which were selected through two-sample $t$ test $(p<0.01)$. $\mathrm{p}<0.01^{* *}, \mathrm{p}<0.001^{* * *}$. The relative intensities of these peaks were up-regulated (a) or down-regulated (b) in the tumor tissues compared with adjacent para-tumor tissues. 

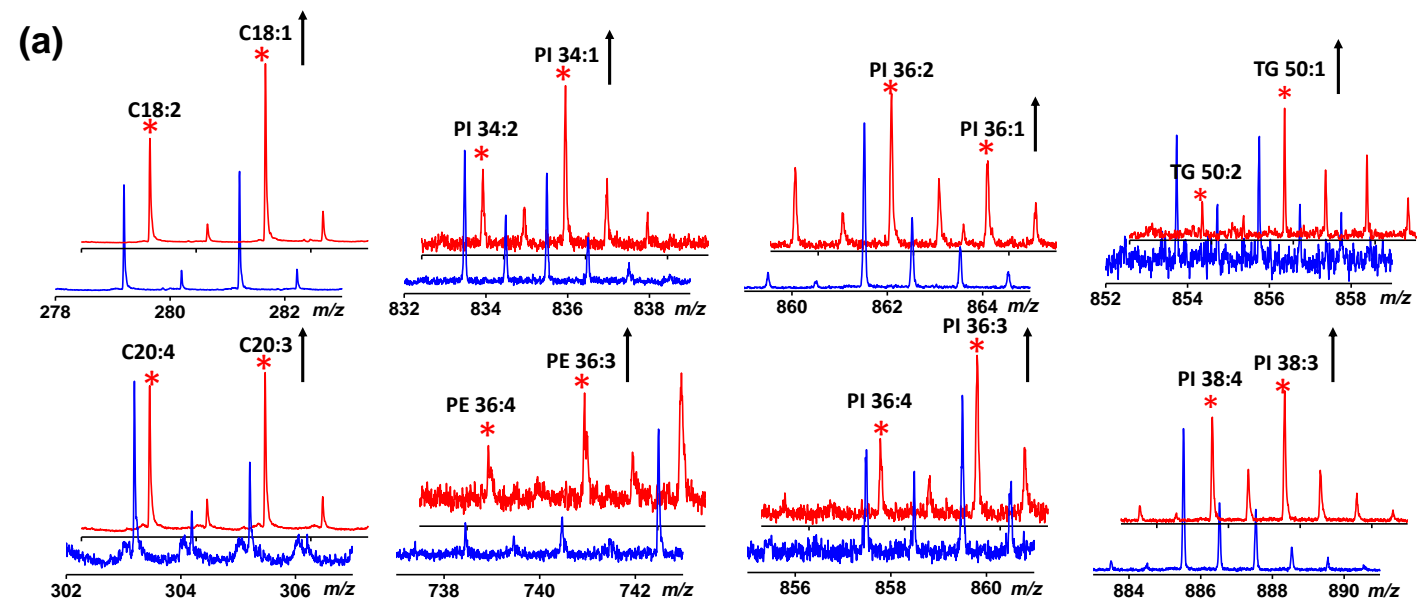

(b)

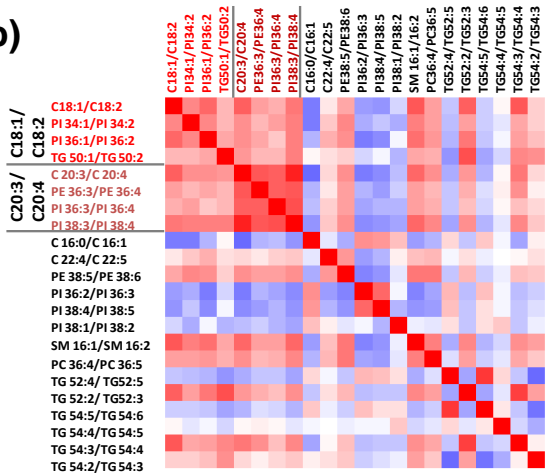

(c)

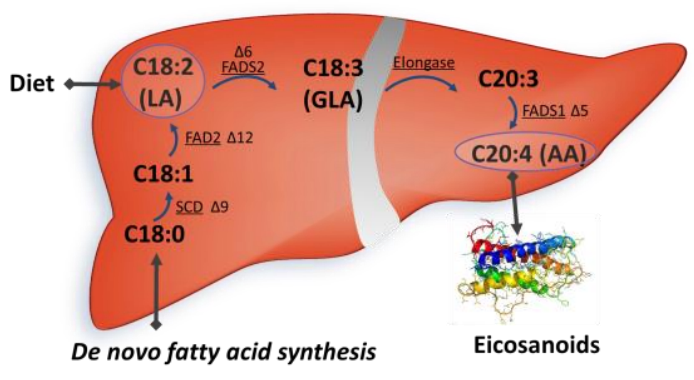

Figure S9. (a) Magnified mass spectra of lipid profiles at the $\mathrm{m} / \mathrm{z}$ range of 8 pair dual-peaks (Specimen no. 1). Red lines refer to $T$ and blue lines refer to $P T$. (b) Pearson correlation matrix among 22 feature ratios. (c) Scheme of linoleic acid metabolism in the liver. LA: linoleic acid; GLA: $\gamma$-linoleic acid; AA: arachidonic acid; SCD: stearoyl CoA desaturase; FAD2: delta-12 fatty acid desaturase; FADS2: delta-6 fatty acid desaturase; FADS1: delta-5 fatty acid desaturase. 
(a) $\quad$ Region (1): $T$

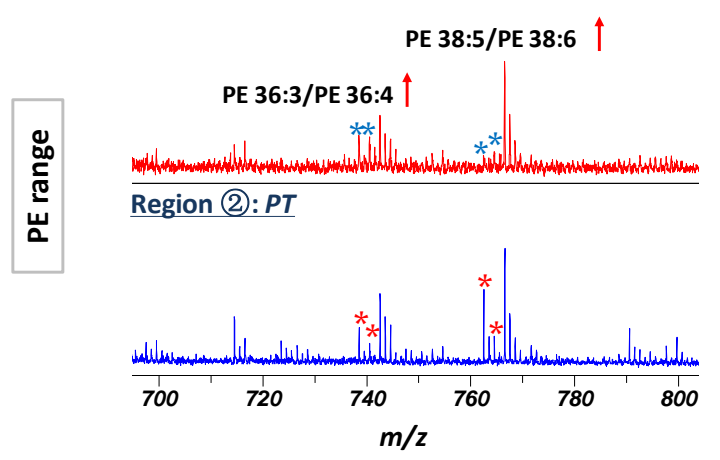

(c) Region (1):T

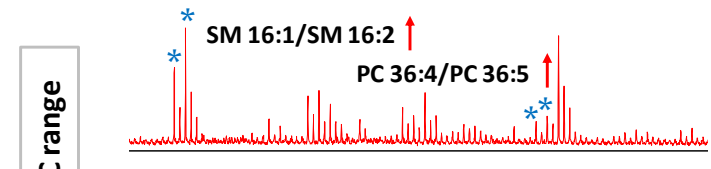

Region (2): PT

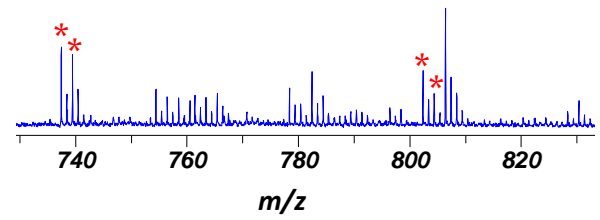

(b) Region (1): $T$ PI 36:3/PI 36:4 $\uparrow$ $\mathrm{PI} 34: 1 / \mathrm{PI} 34: 2 \uparrow \mathrm{PI} 36: 2 / \mathrm{PI} 36: 3 \downarrow$ PI 38:3/PI 38:4

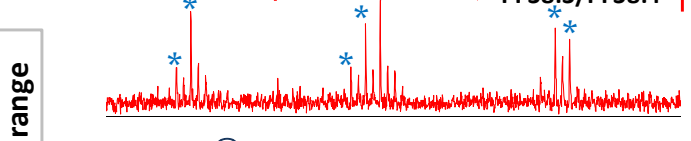

Region (2): PT

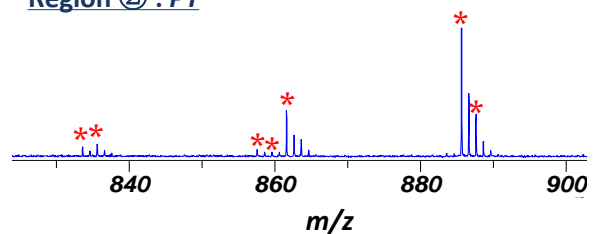

(d)

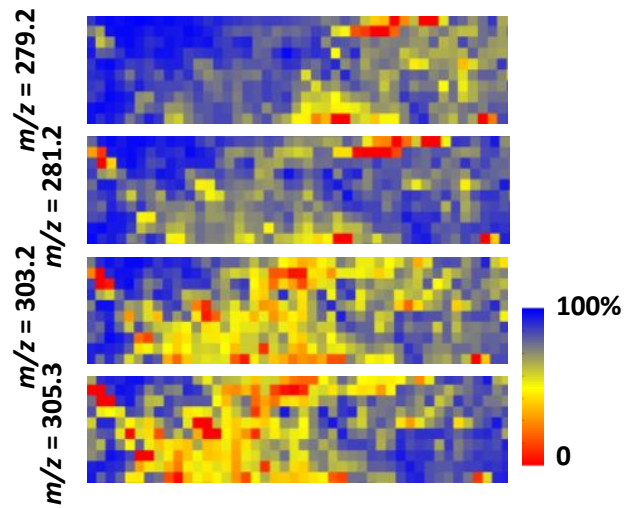

Figure S10. (a-c) Representative mass spectra detected on region $1(T)$ and region $2(P T)$ at the PE (a), PI (b) and SM \& PC (c) range of specimen no. 21. (d) Single-peak digital imaging result of C18:2 $(\mathrm{m} / \mathrm{z}=279.2), \mathrm{C} 18: 1(\mathrm{~m} / \mathrm{z}=281.2), \mathrm{C} 20: 4(\mathrm{~m} / \mathrm{z}=303.2)$ and $\mathrm{C} 20: 3(\mathrm{~m} / \mathrm{z}=305.3)$ of no. 21 HCC tissue sample.

Table S1. Demographic information of $20 \mathrm{HCC}$ patients

\begin{tabular}{|c|c|c|c|c|c|c|c|}
\hline \multicolumn{4}{|c|}{ Information of Tissues } & \multicolumn{4}{|c|}{ Information of HCC Patients } \\
\hline Tissue Sample & $\begin{array}{c}\text { Number } \\
\text { (n) }\end{array}$ & Differentiation & $\mathbf{n}$ & Age & $\mathbf{n}$ & Gender & $\mathbf{n}$ \\
\hline \multirow{4}{*}{ Tumor $(T)$} & \multirow{4}{*}{20} & Low & 5 & \multirow{2}{*}{$<50 \mathrm{y}$} & \multirow{2}{*}{5} & \multirow{3}{*}{ Male } & \multirow{3}{*}{18} \\
\hline & & Medium & 8 & & & & \\
\hline & & High & 4 & \multirow{2}{*}{$50-70$ y } & \multirow{2}{*}{12} & & \\
\hline & & $\mathrm{ND}^{\mathrm{a}}$ & 3 & & & \multirow{3}{*}{ Female } & \multirow{3}{*}{2} \\
\hline Para-tumor $(P T)$ & 20 & l & I & \multirow{2}{*}{$>70 y$} & \multirow{2}{*}{3} & & \\
\hline Normal $(N)$ & 20 & I & I & & & & \\
\hline
\end{tabular}

${ }^{a}$ ND means no data was acquired from clinical diagnosis. 
Table S2. Detailed diagnostic information of HCC patients

\begin{tabular}{|c|c|c|c|c|c|}
\hline No. & $\begin{array}{l}\text { Histologic } \\
\text { type }\end{array}$ & $\begin{array}{c}\text { Primary } \\
\text { or } \\
\text { secondary }\end{array}$ & Differentiation & Pathology of cancerous tissue & $\begin{array}{c}\text { Patient } \\
\text { information }\end{array}$ \\
\hline 1 & $\mathrm{HCC}$ & Primary & Medium & Hepatocyte(+), Arginase-1(+), Glypican-3(+), AFP(+), CK7(-), CK19(-) & Male, 53 \\
\hline 2 & $\mathrm{HCC}$ & Primary & High & Hepatocyte(+), Arginase-1(+), Glypican-3(+), AFP(+), CK7(-), CK19(-) & Female, 70 \\
\hline 3 & $\mathrm{HCC}$ & Primary & Low & $\begin{array}{l}\text { Hepatocyte (+), Arginase-1(+), Glypican-3(+), AFP(-), CK7(+), CK19(+), } \\
\text { CEA-R(+), CD34(-) }\end{array}$ & Male, 70 \\
\hline 4 & $\mathrm{HCC}$ & Primary & Low & $\begin{array}{l}\text { Hepatocyte }(+), \text { Arginase-1(+), Glypican-3(+), AFP(+), CK7(+), CK19(-), } \\
\text { CEA-R(+), CD34(+) }\end{array}$ & Male, 40 \\
\hline 5 & $\mathrm{HCC}$ & Primary & Low & $\begin{array}{l}\text { Hepatocyte(+), Arginase-1(+), Glypican-3(-), AFP(-), CK7(-), CK19(-), } \\
\text { CEA-R(+), CD34(+) }\end{array}$ & Male, 80 \\
\hline 6 & $\mathrm{HCC}$ & Primary & High & $\begin{array}{l}\text { Hepatocyte(+), Arginase-1(+), Glypican-3(+), AFP(-), CK7(-), CK19(-), } \\
\text { CEA-R(+) }\end{array}$ & Male, 70 \\
\hline 7 & $\mathrm{HCC}$ & Primary & Medium & Hepatocyte(+), Arginase-1(+), Glypican-3(+), AFP(-), CK7(+), CK19(-) & Male, 46 \\
\hline 8 & $\mathrm{HCC}$ & Primary & Medium & AFP(+), Hepatocyte(+), Glypican-3(+), Arginase-1(+), CK7(-), CK19(-) & Male, 54 \\
\hline 9 & $\mathrm{HCC}$ & Primary & Medium & Hepatocyte(+), Glypican-3(+), CEA-R(+), AFP(+), CK7(+), CK19(+), CD34(+) & Male, 48 \\
\hline 10 & $\mathrm{HCC}$ & Primary & ND & $\begin{array}{l}\text { Hepatocyte(+), CK7(+), CK19(-), CD34(+), Arginase-1(+), Glypican-3(+), } \\
\text { AFP(-), CEA-R }(+)\end{array}$ & Male, 72 \\
\hline 11 & $\mathrm{HCC}$ & Primary & Medium & $\begin{array}{l}\text { Hepatocyte(+), Glypican-3(+), CD34(+), CEA-R(+), AFP(-), Arginase-1(-), } \\
\text { CK7(-), CK19(-) }\end{array}$ & Male, 69 \\
\hline 12 & $\mathrm{HCC}$ & Primary & ND & Hepatocyte(+), Glypican-3(+), AFP(-), Arginase-1(+), CD34(+), CK7(-), CK19(-) & Male, 62 \\
\hline
\end{tabular}




\begin{tabular}{|c|c|c|c|c|c|}
\hline No. & $\begin{array}{l}\text { Histologic } \\
\text { type }\end{array}$ & $\begin{array}{c}\text { Primary } \\
\text { or } \\
\text { secondary }\end{array}$ & Differentiation & Pathology of cancerous tissue & $\begin{array}{c}\text { Patient } \\
\text { information }\end{array}$ \\
\hline 13 & $\mathrm{HCC}$ & Primary & Medium & $\begin{array}{l}\text { AFP(-), Arginase-1(-), CEA-R(+), Glypican-3(+), Hepatocyte(+), CK7(-), } \\
\text { CD34(+), CK19(-) }\end{array}$ & Male, 63 \\
\hline 14 & $\mathrm{HCC}$ & Primary & Low & $\begin{array}{l}\text { Hepatocyte(+), Glypican-3(+), Arginase-1(+), AFP(-), CK7(-), CK19(-), } \\
\text { CEA-R(+), CD34(+) }\end{array}$ & Male, 55 \\
\hline 15 & $\mathrm{HCC}$ & Primary & Medium & $\begin{array}{l}\text { Hepatocyte(+), Glypican-3(+), AFP(+), Arginase-1(+), CEA-R(+), CD34(+), } \\
\text { CK7(-), CK19(-) }\end{array}$ & Male, 64 \\
\hline 16 & $\mathrm{HCC}$ & Primary & Low & $\begin{array}{l}\text { Hepatocyte(+), Glypican-3(-), Arginase-1(-), GS(+), AFP(-), CD34(+), CK7(-), } \\
\text { CK19(-) }\end{array}$ & Male, 55 \\
\hline 17 & $\mathrm{HCC}$ & Primary & High & $\begin{array}{l}\text { Hepatocyte(+), Glypican-3(+), GS(+), CEA-R(+), CD34(+), Arginase-1(-), } \\
\text { CK7(-), CK19(-), AFP(-) }\end{array}$ & Male, 73 \\
\hline 18 & $\mathrm{HCC}$ & Primary & ND & No data & Male, 46 \\
\hline 19 & $\mathrm{HCC}$ & Primary & High & $\begin{array}{l}\text { Hepatocyte(+), AFP(-), GS(+), Arginase-1(+), Glypican-3(+), CD34(+), } \\
\text { CEA-R(+), CK7(-), CK19(-) }\end{array}$ & Female, 63 \\
\hline 20 & $\mathrm{HCC}$ & Primary & Medium & $\begin{array}{l}\text { Hepatocyte(+), Glypican-3(+), GS(+), Arginase-1(+), AFP(-), CEA-R(+), CK7(+), } \\
\text { CK19(-) }\end{array}$ & Male, 40 \\
\hline $21^{\mathrm{a}}$ & $\mathrm{HCC}$ & Primary & High & $\begin{array}{l}\text { Hepatocyte(+), Glypican-3(+), Arginase-1(+), GS(+), AFP(-), CK7(-), CK19(-), } \\
\text { CEA-R(+), CD34(+) }\end{array}$ & Male, 67 \\
\hline
\end{tabular}

a Tumor and para-tumor tissues of no. 21 were connected together; no. 21 sample was applied for MS imaging and its data was not included in the statistical analysis. 
Table S3. MS/MS fragmental information of different types of lipid species

\begin{tabular}{|c|c|c|c|c|c|}
\hline Class & Identification & Adductive ions & Measured $m / z$ & Theoretical $m / z$ & Main fragments \\
\hline \multirow{3}{*}{ PE } & $\begin{array}{c}34: 2(16: 1 / 18: 1 \text { or } \\
16: 0 / 18: 2)\end{array}$ & {$[\mathrm{M}-\mathrm{H}]^{-}$} & 714.57 & 714.5079 & $\begin{array}{l}452.3,281.2\left([\mathrm{C} 18: 1-\mathrm{H}]^{-}\right), 279.2\left([\mathrm{C} 18: 2-\mathrm{H}]^{-}\right), 255.2 \\
\left([\mathrm{C} 16: 0-\mathrm{H}]^{-}\right), 253.2\left([\mathrm{C} 16: 1-\mathrm{H}]^{-}\right), 153,140,97,79\end{array}$ \\
\hline & $\begin{array}{c}36: 2(18: 1 / 18: 1 \text { or } \\
18: 0 / 18: 2)\end{array}$ & {$[\mathrm{M}-\mathrm{H}]^{-}$} & 742.62 & 742.5392 & $\begin{array}{l}480.3,478.3,476.3,462.3,283.3,281.2,279.2,153,140 \text {, } \\
122,97,79\end{array}$ \\
\hline & $\begin{array}{c}38: 4(18: 0 / 20: 4 \text { or } \\
18: 1 / 20: 3)\end{array}$ & {$[\mathrm{M}-\mathrm{H}]^{-}$} & 766.64 & 766.5392 & $\begin{array}{l}\left.\text { 480.3, 478.3, 462.3, 303.3([C20:4-H }]^{-}\right) \\
305.3\left(\left[\mathrm{C} 20: 3-\mathrm{H}^{-}\right), 283.3,281.2,153,140,97,79\right.\end{array}$ \\
\hline \multirow{4}{*}{ PI } & $\begin{array}{c}34: 1(16: 1 / 18: 1 \text { or } \\
16: 0 / 18: 2)\end{array}$ & {$[\mathrm{M}-\mathrm{H}]^{-}$} & 835.56 & 835.5342 & $\begin{array}{l}581.3,579.3,553.3,419.3,417.2,391.2,389.2,315,297, \\
283.2,281.2,259,255.2,253.2,241,223,153,97,79\end{array}$ \\
\hline & $\begin{array}{c}36: 2(18: 0 / 18: 2 \text { or } \\
18: 1 / 18: 1)\end{array}$ & {$[\mathrm{M}-\mathrm{H}]^{-}$} & 861.58 & 861.5499 & $\begin{array}{l}581.3,419.3,297,283.2,281.2,279.2,259,255.2,253.2 \\
241,223,153,97,79\end{array}$ \\
\hline & $38: 4(18: 0 / 20: 4)$ & {$[\mathrm{M}-\mathrm{H}]^{-}$} & 885.58 & 885.5499 & $\begin{array}{l}599.3,581.3,437.2,419,315,303.3,297,283.3, \quad 259, \\
241,223,153,97,79\end{array}$ \\
\hline & $38: 3(18: 0 / 20: 3)$ & {$[\mathrm{M}-\mathrm{H}]^{-}$} & 887.52 & 887.5655 & $599.3,419,303.3,283.3,241,153,97,79$ \\
\hline \multirow{7}{*}{ SM } & $\mathrm{d} 18: 1 / \mathrm{C} 14: 1$ & {$[\mathrm{M}+\mathrm{K}]^{+}$} & 711.48 & 711.4843 & $184,163,147$ \\
\hline & $\mathrm{d} 18: 1 / \mathrm{C} 14: 0$ & {$[\mathrm{M}+\mathrm{K}]^{+}$} & 713.50 & 713.5000 & $551.5,184,163,147$ \\
\hline & $\mathrm{d} 18: 1 / \mathrm{C} 16: 2$ & {$[\mathrm{M}+\mathrm{K}]^{+}$} & 737.45 & 737.5000 & $184,163,147$ \\
\hline & $\mathrm{d} 18: 1 / \mathrm{C} 16: 1$ & {$[\mathrm{M}+\mathrm{K}]^{+}$} & 739.52 & 739.5156 & $577.5,184,163,147$ \\
\hline & $\mathrm{d} 18: 1 / \mathrm{C} 16: 0$ & {$[\mathrm{M}+\mathrm{K}]^{+}$} & 741.50 & 741.5313 & $184,163,147$ \\
\hline & $\mathrm{d} 18: 1 / \mathrm{C} 18: 2$ & {$[\mathrm{M}+\mathrm{K}]^{+}$} & 765.49 & 765.5307 & $720.5\left(\left[\mathrm{M}-\mathrm{NH}\left(\mathrm{CH}_{3}\right)_{2}+\mathrm{K}\right]^{+}\right), 603.5,184,163,147$ \\
\hline & $\mathrm{d} 18: 1 / \mathrm{C} 18: 1$ & {$[\mathrm{M}+\mathrm{K}]^{+}$} & 767.51 & 765.5464 & $184,163,147$ \\
\hline
\end{tabular}




\begin{tabular}{|c|c|c|c|c|c|}
\hline Class & Identification & Adductive ions & Measured $m / z$ & Theoretical $\mathrm{m} / \mathrm{z}$ & Main fragments \\
\hline \multirow{16}{*}{ PC } & $32: 1$ & {$[\mathrm{M}+\mathrm{Na}]^{+}$} & 754.53 & 754.5363 & $571.5\left([\mathrm{M}+\mathrm{Na}-183]^{+}\right), 549.5\left([\mathrm{M}-183]^{+}\right), 184,163,147$ \\
\hline & \multirow{2}{*}{$32: 0$} & {$[\mathrm{M}+\mathrm{Na}]^{+}$} & 756.54 & 756.5519 & $573.5,551.5,184,163,147$ \\
\hline & & {$[\mathrm{M}+\mathrm{K}]^{+}$} & 772.51 & 772.5259 & $713\left([\mathrm{M}+\mathrm{K}-59]^{+}\right), 551\left([\mathrm{M}-183]^{+}\right), 184,163,147$ \\
\hline & $34: 3$ & {$[\mathrm{M}+\mathrm{Na}]^{+}$} & 778.54 & 778.5363 & $595.5,573.5,184,163,147$ \\
\hline & \multirow{2}{*}{$34: 2$} & {$[\mathrm{M}+\mathrm{H}]^{+}$} & 758.57 & 758.5700 & $597.5,575.5,184,163,147$ \\
\hline & & {$[\mathrm{M}+\mathrm{Na}]^{+}$} & 780.54 & 780.5519 & $597.5,575.5,184,163,147$ \\
\hline & \multirow{3}{*}{$34: 1$} & {$[\mathrm{M}+\mathrm{H}]^{+}$} & 760.55 & 760.5856 & $599.5,577.5,265,184,163,147$ \\
\hline & & {$[\mathrm{M}+\mathrm{Na}]^{+}$} & 782.57 & 782.5676 & $\begin{array}{l}739.5\left([\mathrm{M}+\mathrm{K}-59]^{+}\right), 723.5\left([\mathrm{M}+\mathrm{Na}-59]^{+}\right), 599.5 \\
\left([\mathrm{M}+\mathrm{Na}-183]^{+}\right), 577.5\left([\mathrm{M}-183]^{+}\right), 184,163,147\end{array}$ \\
\hline & & {$[\mathrm{M}+\mathrm{K}]^{+}$} & 798.54 & 798.5415 & $739,615,599,577,184,163,147$ \\
\hline & $34: 0$ & {$[\mathrm{M}+\mathrm{Na}]^{+}$} & 784.56 & 784.5832 & $741,184,163,147$ \\
\hline & $36: 5$ & {$[\mathrm{M}+\mathrm{Na}]^{+}$} & 802.55 & 802.5363 & $\begin{array}{l}759.5,742.5,619.5,526.5\left([\mathrm{M}+\mathrm{Na}-\mathrm{C} 18: 4]^{+}\right), 524.5 \\
\left([\mathrm{M}+\mathrm{Na}-\mathrm{C} 18: 3]^{+}\right), 522.5\left([\mathrm{M}+\mathrm{Na}-\mathrm{C} 18: 2]^{+}\right), 520.5 \\
\left([\mathrm{M}+\mathrm{Na}-\mathrm{C} 18: 1]^{+}\right), 184,163,147\end{array}$ \\
\hline & $36: 4$ & {$[\mathrm{M}+\mathrm{Na}]^{+}$} & 804.53 & 804.5519 & $761.5,621.5,184,163,147$ \\
\hline & \multirow{2}{*}{$36: 3$} & {$[\mathrm{M}+\mathrm{Na}]^{+}$} & 806.57 & 806.5676 & $\begin{array}{l}763.5\left([\mathrm{M}+\mathrm{K}-59]^{+}\right), 623.5\left([\mathrm{M}+\mathrm{Na}-183]^{+}\right), 601.5 \\
\left([\mathrm{M}-183]^{+}\right), 184,163,147\end{array}$ \\
\hline & & {$[\mathrm{M}+\mathrm{K}]^{+}$} & 822.54 & 822.5415 & $\begin{array}{l}763.5\left([\mathrm{M}+\mathrm{K}-59]^{+}\right), 601.5\left([\mathrm{M}-183]^{+}\right), 544.5 \\
\left([\mathrm{M}+\mathrm{K}-\mathrm{C} 18: 3]^{+}, 184,163,147\right.\end{array}$ \\
\hline & $36: 2$ & {$[\mathrm{M}+\mathrm{Na}]^{+}$} & 808.58 & 808.5832 & $765.5,184,163,147$ \\
\hline & $36: 1$ & {$[\mathrm{M}+\mathrm{Na}]^{+}$} & 810.60 & 810.5889 & $767.5,627.5,184,163,147$ \\
\hline
\end{tabular}




\begin{tabular}{|c|c|c|c|c|c|}
\hline & Identification & Adductive ions & Measured $m / z$ & Theoretical $\mathrm{m} / \mathrm{z}$ & Main fragments \\
\hline & \multirow[b]{2}{*}{$38: 6$} & {$[\mathrm{M}+\mathrm{Na}]^{+}$} & 828.56 & 828.5519 & 785.5, 645.5, $544.5\left([\mathrm{M}+\mathrm{Na}-\mathrm{C} 18: 0]^{+}\right), 184,163,147$ \\
\hline & & {$[\mathrm{M}+\mathrm{K}]^{+}$} & 844.54 & 844.5259 & $\begin{array}{l}785.5\left([\mathrm{M}+\mathrm{K}-59]^{+}\right), 661.5\left([\mathrm{M}+\mathrm{K}-183]^{+}\right), 560.5 \\
\left.(\mathrm{M}+\mathrm{K}-\mathrm{C} 18: 0]^{+}\right), 562.5\left([\mathrm{M}+\mathrm{K}-\mathrm{C} 18: 1]^{+}\right), 564.5 \\
\left([\mathrm{M}+\mathrm{K}-\mathrm{C} 18: 2]^{+}\right) ; 540.5\left([\mathrm{M}+\mathrm{K}-\mathrm{C} 20: 4]^{+}\right), 542.5 \\
\left([\mathrm{M}+\mathrm{K}-\mathrm{C} 20: 5]^{+}\right), 544.5\left([\mathrm{M}+\mathrm{K}-\mathrm{C} 20: 6]^{+}\right), 184,163,147\end{array}$ \\
\hline & \multirow[b]{2}{*}{$38: 5$} & {$[\mathrm{M}+\mathrm{Na}]^{+}$} & 830.58 & 830.5675 & $787,647,184,163,147$ \\
\hline & & {$[\mathrm{M}+\mathrm{K}]^{+}$} & 846.53 & 846.5415 & $\begin{array}{l}566.5\left([\mathrm{M}+\mathrm{K}-\mathrm{C} 18: 2]^{+}\right), 540.5\left([\mathrm{M}+\mathrm{K}-\mathrm{C} 20: 3]^{+}\right), 184,163 \text {, } \\
147\end{array}$ \\
\hline & $38: 4$ & {$[\mathrm{M}+\mathrm{Na}]^{+}$} & 832.59 & 832.5832 & $649.5,627.5,552.5\left([\mathrm{M}+\mathrm{Na}-\mathrm{C} 18: 2]^{+}\right), 184,163,147$ \\
\hline & $38: 3$ & {$[\mathrm{M}+\mathrm{Na}]^{+}$} & 834.60 & 834.5989 & $651.5,629.5,552.5\left([\mathrm{M}+\mathrm{Na}-\mathrm{C} 18: 1]^{+}\right), 184,163,147$ \\
\hline & $38: 2$ & {$[\mathrm{M}+\mathrm{Na}]^{+}$} & 836.61 & 836.6145 & $552.5\left([\mathrm{M}+\mathrm{Na}-\mathrm{C} 18: 0]^{+}\right), 184,163,147$ \\
\hline & $38: 1$ & {$[\mathrm{M}+\mathrm{Na}]^{+}$} & 838.63 & 838.6302 & $795.5,184,163,147$ \\
\hline \multirow{4}{*}{ PS } & $38: 3$ & {$[\mathrm{M}+\mathrm{Na}]^{+}$} & 864.57 & 864.5731 & 779.6.5, 584.3, 497.3, 299, 223 \\
\hline & $38: 2$ & {$[\mathrm{M}+\mathrm{Na}]^{+}$} & 866.59 & 866.5887 & $\begin{array}{l}779.6,584.3\left([\mathrm{M}-\mathrm{C} 18: 0+\mathrm{Na}]^{+}\right), 497.3 \\
\left(\left[\mathrm{M}-\mathrm{C} 18: 0-\mathrm{C}_{3} \mathrm{H}_{5} \mathrm{O}_{2} \mathrm{~N}+\mathrm{Na}\right]^{+}\right), 299,223\end{array}$ \\
\hline & $38: 1$ & {$[\mathrm{M}+\mathrm{Na}]^{+}$} & 868.61 & 868.6044 & $779.6,584.3,497.3,299,223$ \\
\hline & $38: 0$ & {$[\mathrm{M}+\mathrm{Na}]^{+}$} & 870.63 & 870.6200 & $779.6,584.3,497.3,299,223$ \\
\hline
\end{tabular}




\begin{tabular}{|c|c|c|c|c|c|}
\hline Class & Identification & Adductive ions & Measured $m / z$ & Theoretical $\mathrm{m} / z$ & Main fragments \\
\hline \multirow{7}{*}{ TG } & \multirow[t]{2}{*}{$\begin{array}{c}50: 2 \\
(16: 0 / 16: 1 / 18: 1)\end{array}$} & {$[\mathrm{M}+\mathrm{Na}]^{+}$} & 853.68 & 853.7261 & $\begin{array}{l}831.7\left([\mathrm{M}+\mathrm{H}]^{+}\right), 599.5\left([\mathrm{M}-\mathrm{C} 16: 1+\mathrm{Na}]^{+}\right), 597.5 \\
\left([\mathrm{M}-\mathrm{C} 16: 0+\mathrm{Na}]^{+}\right), 577.5\left([\mathrm{M}-\mathrm{C} 16: 1]^{+}\right), 575.5 \\
\left([\mathrm{M}-\mathrm{C} 16: 0]^{+}\right), 549.5 \quad\left([\mathrm{M}-\mathrm{C} 18: 1]^{+}\right), 321.3,295.3,293.3, \\
265.3,239.2,237.2\end{array}$ \\
\hline & & {$[\mathrm{M}+\mathrm{K}]^{+}$} & 869.65 & 869.7000 & $599.5,597.5,577.5,575.5,321.3,295.3,293.3,265.3$ \\
\hline & \multirow[t]{2}{*}{$\begin{array}{c}52: 2 \\
(16: 0 / 18: 1 / 18: 1 \text { or } \\
16: 1 / 18: 0 / 18: 1)\end{array}$} & {$[\mathrm{M}+\mathrm{Na}]^{+}$} & 881.71 & 881.7574 & $\begin{array}{l}627.5\left([\mathrm{M}-\mathrm{C} 16: 1+\mathrm{Na}]^{+}\right), 625.5\left([\mathrm{M}-\mathrm{C} 16: 0+\mathrm{Na}]^{+}\right), 605.5 \\
\left([\mathrm{M}-\mathrm{C} 16: 1]^{+}\right), 603.5\left([\mathrm{M}-\mathrm{C} 16: 0]^{+}\right), 599.5 \\
\left([\mathrm{M}-\mathrm{C} 18: 1+\mathrm{Na}]^{+}\right), 597.5\left([\mathrm{M}-\mathrm{C} 18: 0+\mathrm{Na}]^{+}\right), 577.5 \\
\left([\mathrm{M}-\mathrm{C} 18: 1]^{+}\right), 575.5\left([\mathrm{M}-\mathrm{C} 18: 0]^{+}\right), 321.3,295.3,265.3 \\
239.2\end{array}$ \\
\hline & & {$[\mathrm{M}+\mathrm{K}]^{+}$} & 897.68 & 897.7313 & $605.5,603.5,599.5,597.5,577.5,575.5,321.3,295.3$ \\
\hline & $\begin{array}{c}54: 4 \\
(18: 1 / 18: 1 / 18: 2)\end{array}$ & {$[\mathrm{M}+\mathrm{Na}]^{+}$} & 905.71 & 905.7574 & $\begin{array}{l}625.5,623.5,603.5,601.5,339.3,321.3,319.3,265.3, \\
263.2,247.2\end{array}$ \\
\hline & $\begin{array}{c}54: 3 \\
(18: 1 / 18: 1 / 18: 1 \text { or } \\
18: 0 / 18: 1 / 18: 2)\end{array}$ & {$[\mathrm{M}+\mathrm{K}]^{+}$} & 923.70 & 923.7470 & $605.5,603.5,601.5,323.3,321.3,319.3$ \\
\hline & $\begin{array}{c}56: 4 \\
(18: 1 / 18: 1 / 20: 2 \text { or } \\
18: 1 / 18: 2 / 20: 1)\end{array}$ & {$[\mathrm{M}+\mathrm{Na}]^{+}$} & 933.75 & 933.7887 & $\begin{array}{l}653.5,651.5,631.5,629.5,625.5,623.5,603.5,601.5 \\
347.3,321.3,319.3,293.3,265.2,263.2\end{array}$ \\
\hline
\end{tabular}


Table S4. $p$ value summary of feature ratios calculated with two-sample t test

\begin{tabular}{|c|c|c|c|c|}
\hline Ratios & $T$ vs $P T$ & $T$ vs $N$ & $P T$ vs $N$ & Tendency in $T$ \\
\hline C16:0/C16:1 & $7.87 \times 10^{-9}$ & $8.62 \times 10^{-8}$ & 0.546 & $\downarrow$ \\
\hline C18:1/C18:2 & $3.78 \times 10^{-6}$ & $2.66 \times 10^{-8}$ & 0.449 & $\uparrow$ \\
\hline C20:3/C20:4 & $2.01 \times 10^{-6}$ & $1.41 \times 10^{-7}$ & 0.401 & $\uparrow$ \\
\hline C22:4/C22:5 & $2.26 \times 10^{-3}$ & $9.47 \times 10^{-4}$ & 0.841 & $\uparrow$ \\
\hline PE 36:3/PE 36:4 & $5.30 \times 10^{-3}$ & $8.82 \times 10^{-3}$ & 0.705 & $\uparrow$ \\
\hline PE 38:5/PE 38:6 & $1.91 \times 10^{-7}$ & $3.43 \times 10^{-10}$ & 0.284 & $\uparrow$ \\
\hline PI 34:1/PI 34:2 & $3.06 \times 10^{-11}$ & $1.09 \times 10^{-11}$ & 0.994 & $\uparrow$ \\
\hline PI 36:3/PI 36:4 & $5.29 \times 10^{-3}$ & $3.17 \times 10^{-3}$ & 0.972 & $\uparrow$ \\
\hline PI 36:2/PI 36:3 & $9.85 \times 10^{-7}$ & $2.38 \times 10^{-7}$ & 0.181 & $\downarrow$ \\
\hline PI 36:1/PI 36:2 & $1.55 \times 10^{-12}$ & $5.26 \times 10^{-12}$ & 0.775 & $\uparrow$ \\
\hline PI 38:4/PI 38:5 & $2.41 \times 10^{-5}$ & $1.37 \times 10^{-3}$ & 0.126 & $\downarrow$ \\
\hline PI 38:3/PI 38:4 & $1.24 \times 10^{-10}$ & $2.83 \times 10^{-10}$ & 0.466 & $\uparrow$ \\
\hline PI 38:1/PI 38:2 & $7.91 \times 10^{-4}$ & $2.51 \times 10^{-6}$ & 0.0987 & $\downarrow$ \\
\hline SM 16:1/SM 16:2 & $1.04 \times 10^{-10}$ & $7.36 \times 10^{-10}$ & 0.221 & $\uparrow$ \\
\hline PC 36:4/PC 36:5 & $2.41 \times 10^{-9}$ & $3.80 \times 10^{-11}$ & 0.786 & $\uparrow$ \\
\hline TG 50:1/TG 50:2 & $3.83 \times 10^{-5}$ & $5.44 \times 10^{-4}$ & 0.0420 & $\uparrow$ \\
\hline TG 52:4/TG 52:5 & $2.12 \times 10^{-4}$ & $1.04 \times 10^{-6}$ & 0.0728 & $\downarrow$ \\
\hline TG 52:2/TG 52:3 & $3.37 \times 10^{-6}$ & $5.65 \times 10^{-6}$ & 0.957 & $\uparrow$ \\
\hline TG 54:5/TG 54:6 & $3.95 \times 10^{-5}$ & $2.63 \times 10^{-5}$ & 0.190 & $\downarrow$ \\
\hline TG 54:4/TG 54:5 & $2.16 \times 10^{-3}$ & $4.89 \times 10^{-3}$ & 0.405 & $\downarrow$ \\
\hline TG 54:3/TG 54:4 & $7.71 \times 10^{-4}$ & $2.26 \times 10^{-4}$ & 0.661 & $\uparrow$ \\
\hline TG 54:2/TG 54:3 & $7.14 \times 10^{-3}$ & $5.94 \times 10^{-3}$ & 0.691 & $\uparrow$ \\
\hline
\end{tabular}


Table S5. $p$ value summary of feature peaks calculated with two-sample t test

\begin{tabular}{|c|c|c|c|c|}
\hline Molecules & $m / z$ & $T$ vs $P T$ & $T$ vs $N$ & $P T$ vs $N$ \\
\hline [C16:1-H] $]^{-}$ & 253.22 & $9.44 \times 10^{-6}$ & $1.04 \times 10^{-5}$ & 0.982 \\
\hline [C18:2-H] ${ }^{-}$ & 279.23 & $2.29 \times 10^{-10}$ & $1.28 \times 10^{-11}$ & 0.552 \\
\hline$[\mathrm{C20:3-H}]^{-}$ & 281.25 & $1.07 \times 10^{-6}$ & $7.39 \times 10^{-7}$ & 0.747 \\
\hline [PE 36:2-H] & 742.54 & $3.73 \times 10^{-4}$ & $2.31 \times 10^{-3}$ & 0.486 \\
\hline [PE 38:6-H]' & 762.51 & $4.38 \times 10^{-13}$ & $8.17 \times 10^{-17}$ & 0.355 \\
\hline [PE 38:5-H] & 764.52 & $3.35 \times 10^{-3}$ & $2.27 \times 10^{-3}$ & 0.866 \\
\hline$\left[\mathrm{PE} \mathrm{40:6-H]^{- }}\right.$ & 790.54 & $2.13 \times 10^{-4}$ & $7.66 \times 10^{-5}$ & 0.776 \\
\hline [PI 34:1-H] $]^{-}$ & 835.53 & $5.85 \times 10^{-6}$ & $4.48 \times 10^{-5}$ & 0.568 \\
\hline [PI 36:3-H] $]^{-}$ & 859.53 & $9.95 \times 10^{-7}$ & $1.98 \times 10^{-4}$ & 0.168 \\
\hline [PI 36:1-H] $]^{-}$ & 863.57 & $4.01 \times 10^{-4}$ & $2.11 \times 10^{-3}$ & 0.438 \\
\hline [PI 38:5-H] $]^{-}$ & 883.53 & $1.78 \times 10^{-4}$ & $2.57 \times 10^{-3}$ & 0.242 \\
\hline [PI 38:4-H] $]^{-}$ & 885.55 & $6.20 \times 10^{-5}$ & $3.35 \times 10^{-7}$ & 0.0344 \\
\hline [PI 38:3-H] $]^{-}$ & 887.57 & $1.71 \times 10^{-13}$ & $6.86 \times 10^{-12}$ & 0.143 \\
\hline [PI 38:2-H] $]^{-}$ & 889.58 & $2.08 \times 10^{-8}$ & $2.08 \times 10^{-6}$ & 0.154 \\
\hline [SM 16:2+K] $^{+}$ & 737.50 & $7.64 \times 10^{-11}$ & $7.90 \times 10^{-11}$ & 0.251 \\
\hline$[\mathrm{SM} 16: 1+K]^{+}$ & 739.52 & $3.40 \times 10^{-7}$ & $2.56 \times 10^{-5}$ & 0.428 \\
\hline$[\mathrm{PC} \mathrm{36:5+Na}]^{+}$ & 802.54 & $5.05 \times 10^{-11}$ & $4.32 \times 10^{-13}$ & 0.608 \\
\hline$\left[\mathrm{PC} \mathrm{38:5+Na]^{+ }}\right.$ & 830.57 & $2.29 \times 10^{-4}$ & $9.15 \times 10^{-4}$ & 0.848 \\
\hline 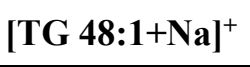 & 827.71 & $1.25 \times 10^{-4}$ & $7.11 \times 10^{-6}$ & 0.527 \\
\hline$[\mathrm{TG} 48: 0+\mathrm{Na}]^{+}$ & 829.73 & $9.49 \times 10^{-4}$ & $3.29 \times 10^{-7}$ & 0.0970 \\
\hline 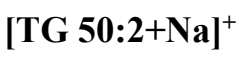 & 853.73 & $9.74 \times 10^{-3}$ & $9.89 \times 10^{-4}$ & 0.229 \\
\hline$[\text { TG 50:1+Na] }]^{+}$ & 855.74 & $7.28 \times 10^{-9}$ & $9.25 \times 10^{-9}$ & 0.918 \\
\hline 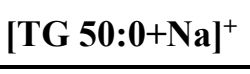 & 857.76 & $7.22 \times 10^{-5}$ & $3.35 \times 10^{-7}$ & 0.228 \\
\hline 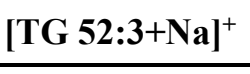 & 879.74 & $5.17 \times 10^{-7}$ & $7.45 \times 10^{-5}$ & 0.423 \\
\hline [TG 52:1+Na] $^{+}$ & 883.77 & $1.12 \times 10^{-3}$ & $1.12 \times 10^{-3}$ & 0.806 \\
\hline
\end{tabular}




\section{Supplementary Reference}

(S1) Li, S.; Ma, W.; Zhou, Y.; Chen, X.; Xiao, Y.; Ma, M.; Wei, F.; Yang, X. J. Solid State Chem. 2014, 213, 242-249.

(S2) Jung, J. Y.; Guo, Z.; Jee, S. W.; Um, H. D.; Park, K. T.; Lee, J. H. Opt. Express 2010, 18 Suppl 3 (19), A286.

(S3) Xiaoli, D.; Jinsheng, C.; Jinghong, L.; Yinsheng, W. Anal. Chem. 2010, 82 (14), 6208-14.

(S4) Chen, X.; Wang, T.; Lin, L.; Wo, F.; Liu, Y.; Liang, X.; Ye, H.; Wu, J. ACS Appl. Mater. Inter. 2018, 10 (17), 14389-14398.

(S5) Murphy, R. C.; Axelsen, P. H. Mass Spectrom. Rev. 2011, 30 (4), 579-99.

(S6) Jackson, S. N.; Wang, H. Y.; Woods, A. S. J. Am. Soc. Mass Spectrom. 2007, 18 (1), 17-26.

(S7) Shrivas, K.; Hayasaka, T.; Goto-Inoue, N.; Sugiura, Y.; Zaima, N.; Setou, M. Anal. Chem. 2010, 82 (21), 8800-6. 